Braz J Med Biol Res, October 2012, Volume 45(10) 929-934

doi: 10.1590/S0100-879X2012007500108

Reversal of the anticoagulant and anti-hemostatic effect of low molecular weight heparin by direct prothrombin activation

S.A. Andrade, L.C. Carrijo-Carvalho, L.A.M. Peceguini, L. Wlian, A.C. Sato, C. Luchiari, E.D. Silva, F.H.A. Maffei and A.M. Chudzinski-Tavassi

The Brazilian Journal of Medical and Biological Research is partially financed by

\section{Q}

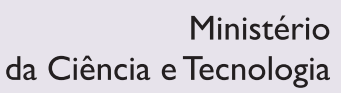

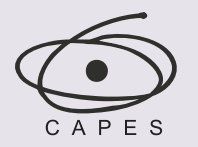

Ministério da Educação
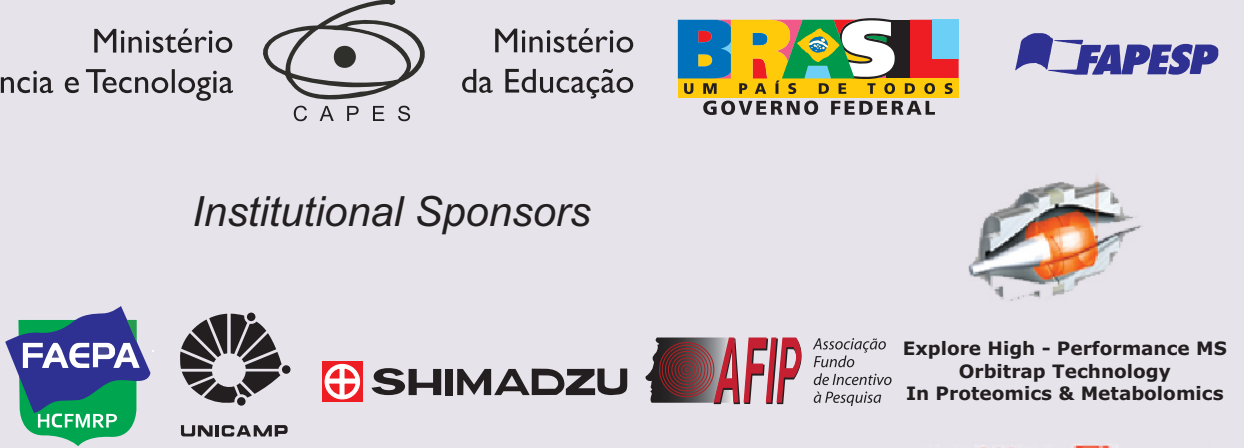

Institutional Sponsors

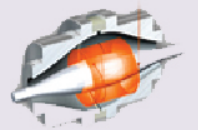

$\oplus$ SHIMADZU UNICAMP

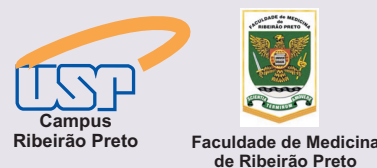
de Ribeirão Preto 


\title{
Reversal of the anticoagulant and anti-hemostatic effect of low molecular weight heparin by direct prothrombin activation
}

\author{
S.A. Andrade ${ }^{1}$, L.C. Carrijo-Carvalho' ${ }^{1}$, L.A.M. Peceguini ${ }^{2}$, L. Wlian ${ }^{1}$, A.C. Sato ${ }^{1}$, \\ C. Luchiari ${ }^{1}$, E.D. Silva ${ }^{2}$, F.H.A. Maffei ${ }^{3,4}$ and A.M. Chudzinski-Tavassi ${ }^{1}$ \\ ${ }^{1}$ Laboratório de Bioquímica e Biofísica, Instituto Butantan, São Paulo, SP, Brasil \\ ${ }^{2}$ Serviço Médico de Anestesia, CET Hospital Sírio-Libanês, São Paulo, SP, Brasil \\ ${ }^{3}$ Faculdade de Medicina de Botucatu, Universidade Estadual Paulista, Botucatu, SP, Brasil \\ ${ }^{4}$ Centro de Estudos e Pesquisas, Hospital Santa Catarina, São Paulo, SP, Brasil
}

\begin{abstract}
Lopap, found in the bristles of Lonomia obliqua caterpillar, is the first exogenous prothrombin activator that shows serine protease-like activity, independent of prothrombinase components and unique lipocalin reported to interfere with hemostasis mechanisms. To assess the action of an exogenous prothrombin activator reversing the anticoagulant and antihemostatic effect induced by low molecular weight heparin (LMWH), male New Zealand rabbits ( $\mathrm{N}=20$, weighing $3.8-4.0 \mathrm{~kg})$ allocated to 4 groups were anticoagulated with $1800 \mathrm{IU} / \mathrm{kg} \mathrm{LMWH}$ (iv) over $2 \mathrm{~min}$, followed by iv administration of saline or recombinant Lopap (rLopap) at $1 \mu \mathrm{g} / \mathrm{kg}$ (LG1) or $10 \mu \mathrm{g} / \mathrm{kg}$ (LG10), $10 \mathrm{~min}$ after the injection of LMWH, in a blind manner. Control animals were treated only with saline. The action of rLopap was assessed in terms of activated partial thromboplastin time (aPTT), prothrombin fragment F1+2, fibrinogen, and ear puncture bleeding time (BT) at 5, 10, 15, 17, 20, 30, 40, 60, and 90 min after initiation of LMWH infusion. LG10 animals showed a decrease of aPTT in more than $50 \%$ and BT near to normal baseline. The level of prothrombin fragment F1+2 measured by ELISA had a 6-fold increase with rLopap treatment $(10 \mu \mathrm{g} / \mathrm{kg})$ and was inversely proportional to BT in LMWH-treated animals. Thus, Lopap, obtained in recombinant form using $E$. coli expression system, was useful in antagonizing the effect of LMWH through direct prothrombin activation, which can be a possible strategy for the reversal of bleeding and anticoagulant events.
\end{abstract}

Key words: Prothrombin activation; Procoagulant; Exogenous hemostatic factor; rLopap; Bleeding; Anticoagulant

\section{Introduction}

Heparin and low molecular weight heparin (LMWH) are widely used for thromboprophylaxis and for the treatment of venous thromboembolic events. Heparin is a heterogeneous mixture of branched glycosaminoglycans, which accelerates anti-thrombin (AT)-derived inactivation of thrombin and, to a lesser extent, coagulation factors Xa and IXa (1-3). LMWHs are derived from cleavage of heparin into a more homogenous mixture of glycosaminoglycans with a mean molecular mass of $5 \mathrm{kDa}$, and LMWHs inhibit factor Xa more effectively than thrombin. Compared to heparin, LMWHs have superior bioavailability, less nonspecific binding, and non-dose-dependent half-lives, which facilitate once or twice daily subcutaneous administration based solely on weight and not requiring monitoring of the patient (4).

Bleeding can be initiated by a reduction or inhibition of coagulation factors, decreased platelet function and increased capillary permeability (3). The effect of unfractionated heparin (UFH) is neutralized with protamine, but this effect is partial on LMWH and only approximately $60 \%$ of the anticoagulant effect can be neutralized. Protamine, an arginine-rich basic cationic protein derived from salmon sperm, has high affinity for negatively charged sulfated glycosaminoglycans, including heparin. Paradoxically, since 1937, protamine has been reported to have anticoagulant

Correspondence: A.M. Chudzinski-Tavassi, Laboratório de Bioquímica e Biofísica, Instituto Butantan, Av. Vital Brasil, 1500, 05503-900 São Paulo, SP, Brasil. Fax: +55-11-3726-1505. E-mail: amchudzinski@butantan.gov.br

Received December 5, 2011. Accepted June 11, 2012. Available online June 29, 2012. Published September 3, 2012. 
activity (4). Thus, an effective antidote for bleeding induced by LWMH is still needed in current clinical care (3-5). The Lonomia obliqua prothrombin activator protease (Lopap) is a $69-\mathrm{kDa}$ tetrameric protein with prothrombin activator activity independent of the prothrombinase compounds, although calcium ions increase its activity. It recognizes and hydrolyzes prothrombin (at concentrations similar to those in human plasma) at the $\mathrm{Arg}^{284}-\mathrm{Thr}^{285}$ peptide bond, leading to the generation of active thrombin, which follows linear kinetics. The thrombin generation starts by prethrombin 2 formation, followed by two consecutive hydrolyses (6).

Recombinant Lopap (rLopap) has been obtained as described by Reis et al. (7) and reproduces the ability of native Lopap to hydrolyze human prothrombin, generating $\alpha$-thrombin. The aim of the present study was to assess the effect of rLopap as an exogenous hemostatic factor in reversing bleeding induced by $\mathrm{LMWH}$ in rabbits.

\section{Material and Methods}

\section{Animal preparation}

The experimental protocol was approved by the Ethics Committee for the Use of Animals of the Teaching and Research Institute, Hospital Sírio-Libanês. Male New Zealand rabbits were randomly allocated to 4 groups of 5 animals each. Anesthesia was induced with ketamine $\mathrm{HCl}(40 \mathrm{mg} /$ $\mathrm{kg}, \mathrm{im}$ ) and xylazine ( $5 \mathrm{mg} / \mathrm{kg}, \mathrm{im}$ ) and was maintained by intermittent injections of the same mixture.

Hair was removed from the ears, neck and upper chest. The animals were monitored and maintained in spontaneous respiration with an oxygen mask. The left femoral artery was dissected free for arterial pressure measurement, the right femoral vein for drug administration and the right jugular vein for blood withdrawal. Animals were sacrificed with an overdose of sodium thiopental (48 mg/kg, iv).

\section{Experimental design}

The animals were treated with LMWH (Enoxaparin, Clexane ${ }^{\circledR}$, Sanofi Aventis Pharmaceutical Ltda., France) as previously described (8). Briefly, rabbits received 1800 $\mathrm{IU} / \mathrm{kg}$ LMWH iv over 2 min, followed by iv administration of saline (SG) or rLopap at a dose of $1 \mu \mathrm{g} / \mathrm{kg}$ (LG1) or $10 \mu \mathrm{g} / \mathrm{kg}$ (LG10), 10 min after the injection of LMWH, in a blind manner. Control animals (CG) were treated only with saline.

\section{Bleeding time}

Ear puncture lesions were made in regions devoid of visible vessels using a No. 11 scalpel blade (Swann Morton, England), creating a full-thickness lesion 3-5 mm in length. One lesion was made in each ear at each time point, beginning at 10 min and immediately prior to LMWH infusion, and at 5, 10, 15, 17, 20, 30, 40, 60, and 90 min after initiation of LMWH infusion according to the study design (Figure 1). Each lesion was identified by a number on the ear using an indelible marker, and blood was absorbed at 30-s intervals onto individual number 1 filter paper discs, $11 \mathrm{~cm}$ in diameter (Whatman International Ltd., UK). The baseline bleeding time (BT) was $1.77 \pm 0.32 \mathrm{~min}$.

\section{Laboratory tests}

Blood samples were obtained from a triple-lumen catheter 10 min prior to LMWH infusion and at 5, 10, 15, 17, $20,30,40,60$, and 90 min after the beginning of LMWH infusion (Figure 1).

Blood was collected at each time point into $3.8 \%$ sodium citrate at the proportion of 9 parts blood to 1 part sodium citrate and kept at $4^{\circ} \mathrm{C}$ until the end of the experiment. On the same day, blood cell counts were determined at all time points with an automated hematology analyzer (ABXPentra 120, ABX Diagnostics, France). The samples were then centrifuged at $2000 \mathrm{~g}$ for $15 \mathrm{~min}$ and evaluated for activated partial thromboplastin time (aPTT), anti-Xa activity, plasma

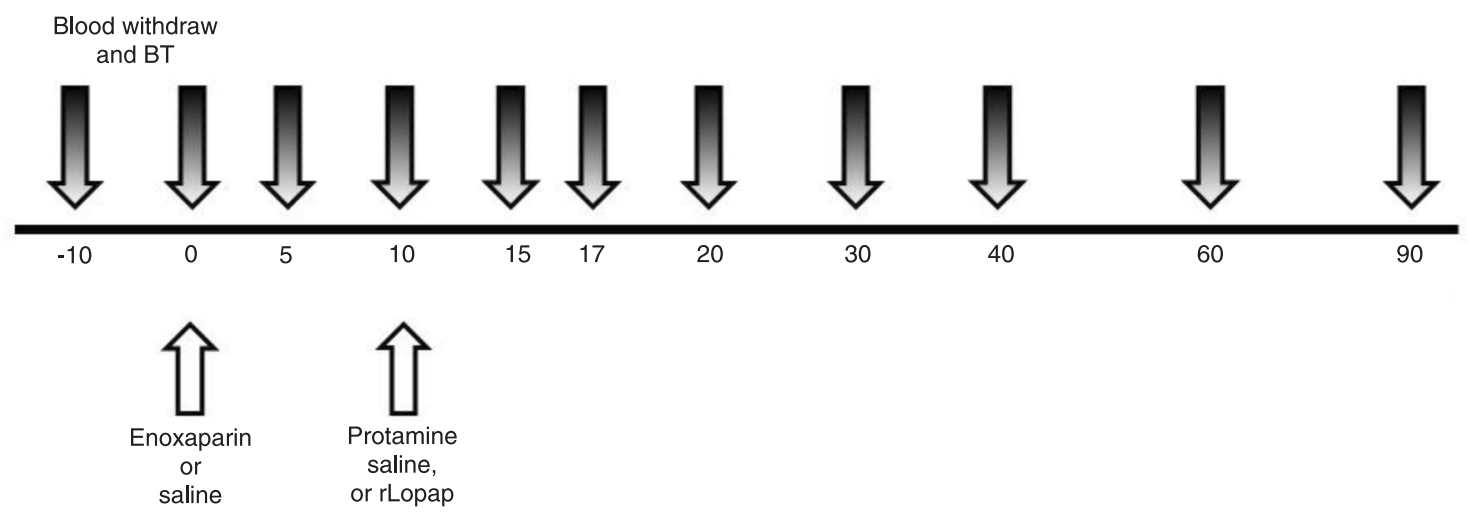

Figure 1. Schematic presentation of the study design. LMWH was infused over 2 min at time 0 , and either rLopap $(1 \mu \mathrm{g}$ or $10 \mu \mathrm{g} / \mathrm{kg}$ ) or saline was infused over $2 \mathrm{~min}$ at $10 \mathrm{~min}$ after the beginning of LMWH infusion. A total of 11 blood samples were collected from each animal at 11 bleeding times (BT). Enoxaparin = low molecular weight heparin (LMWH); rLopap = recombinant Lopap. 
fibrinogen, and prothrombin fragment $1+2$.

Prothrombin fragment $\mathrm{F} 1+2$ was measured by ELISA using the Enzygnost F1+2 kit (Siemens Healthcare Diagnostics, Germany). Measurements were normalized to their baseline (samples collected 10 min before LMWH infusion) and are presented as normalized values.

Plasma LMWH concentration was measured by an antifactor Xa assay (Berichrom Heparin, Dade Behring, Germany). A series of commercial plasma samples of known LMWH concentration was used to construct a standard curve. Residual anti-Xa activity was measured using a chromogenic Xa-specific substrate S2222 (Chromogenix, Sweden).

Fibrinogen and aPTT were measured using standard commercial kits (Helena Laboratories, USA) in a BFT-II coagulometer analyzer (Siemens Healthcare Diagnostics). The test range for the aPTT assay was $28-350 \mathrm{~s}$. In cases where aPTT was above $350 \mathrm{~s}$, it was set at $350 \mathrm{~s}$.
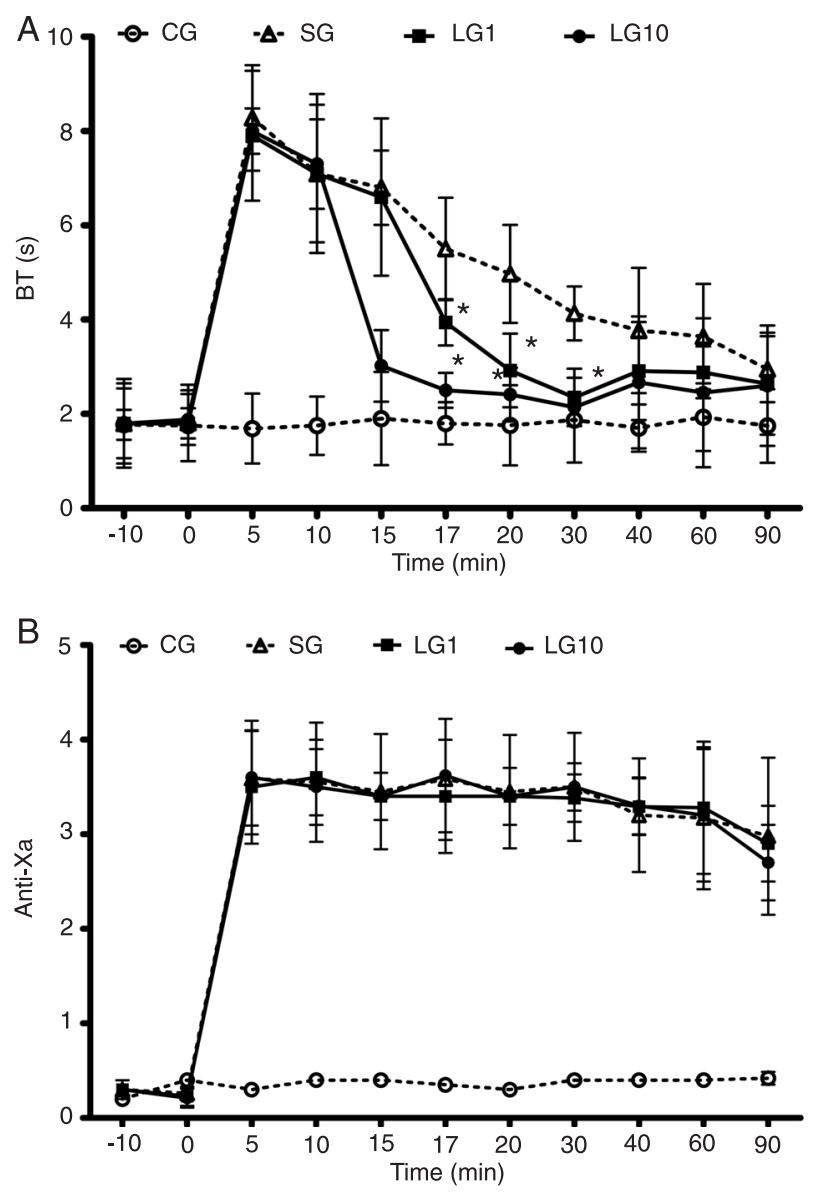

Figure 2. Bleeding time (BT) and anti-factor X activity (anti-Xa). A, BT was evaluated on rabbit ears by a 3-5-mm transfixing incision (with care taken to prevent damage to the artery and vein) with a No. 11 scalpel. $B$, Anti-Xa. $C G=$ Control group; $S G=$ saline group; $L G 1=1$ $\mu \mathrm{g} / \mathrm{kg}$ recombinant Lopap (rLopap); LG10 $=10 \mu \mathrm{g} / \mathrm{kg}$ rLopap. Data are reported as means $\pm S D$ for $N=5$ rabbits per group. ${ }^{*} P<0.01$ vs saline group (ANOVA).

\section{Statistical analyses}

Data are reported as means $\pm S D$. Statistical analysis was performed using the Prism 5.0 software. Differences were determined by one-way analysis of variance (ANOVA), and $P$ values of less than 0.05 were considered to be statistically significant.

\section{Results}

\section{Bleeding and anti-Xa activity}

The injection of LMWH (1800 IU/kg) induced an increase of BT. Five minutes after the administration of $\mathrm{LMWH}$, there was a maximum increase in BT from $1.77 \pm 0.32$ to $8.28 \pm$ $1.12 \mathrm{~min}(\mathrm{~N}=5)$, followed by a gradual decrease within $90 \mathrm{~min}$ (Figure 2A). rLopap or saline was administered 10 min after the injection of LMWH. Treatment with rLopap delayed BT in a dose-dependent manner. LG1 was 2 min slower than LG10 in reducing bleeding, but both concentrations of rLopap reduced bleeding time at 17,20 , and 30 min after LMWH administration compared to SG. At 20 min, a mean BT of $4.97 \pm 1.04$ was observed in the saline group, as opposed to $2.92 \pm 0.78$ in LG1 $(P<0.01)$ and $2.41 \pm 0.57$ in LG10 $(P<0.001)$. BT values returned to normal (near baseline) and no significant difference was observed among groups 80 min after the administration of saline or rLopap. No significant difference was observed at 30 and 50 min after rLopap injection. There were no statistically significant differences in anti-Xa activity (Figure 2B) among the groups at any time point tested.

\section{Clotting parameters}

Activation of coagulation was assessed by measuring F1+2 levels (Figure 3), fibrinogen (Figure 4), and aPTT (Table 1) before and after LMWH and rLopap/saline injections. An increase in $\mathrm{F} 1+2$ levels was observed in the

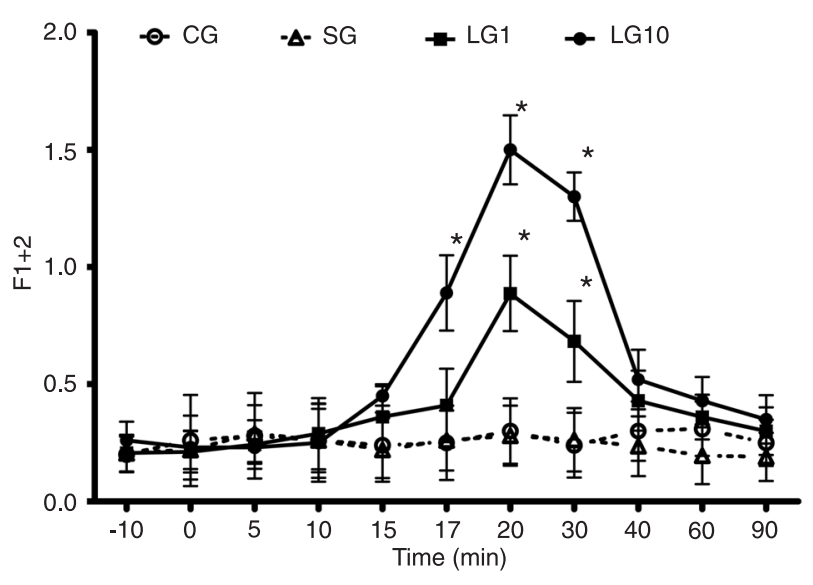

Figure 3. Fragment F1+2 levels measured by ELISA and reported as fold increase over baseline (time -10). CG = Control group; $S G$ = saline group; LG1 = $1 \mu \mathrm{g} / \mathrm{kg}$ recombinant Lopap (rLopap); $\mathrm{LG} 10=10 \mu \mathrm{g} / \mathrm{kg}$ rLopap. Data are reported as means \pm SD for $\mathrm{N}$ $=5$ rabbits per group. ${ }^{*} \mathrm{P}<0.01$ vs saline group (ANOVA). 
rLopap groups compared to CG after $17 \mathrm{~min}$ $(0.89 \pm 0.16, \mathrm{LG} 10$ vs $0.26 \pm 0.13, \mathrm{P}<0.001)$, $20 \min (1.50 \pm 0.15, \mathrm{LG} 10$ and $0.89 \pm 0.16, \mathrm{LG} 1$ vs $0.28 \pm 0.13, P<0.001)$ and $30 \min (1.30 \pm$ $0.10, \mathrm{LG} 10$ and $0.68 \pm 0.17$, LG1 vs $0.26 \pm 0.14$, $\mathrm{P}<0.001$ and $\mathrm{P}<0.01$, respectively). $\mathrm{F} 1+2$ levels remained elevated for 20 min after rLopap treatment, and then decreased and returned to normal by $80 \mathrm{~min}$.

As shown in Figure 4, the fibrinogen levels at 10 and 20 min after the injection of rLopap showed only a slight decrease in LG10 compared to SG. Administration of $1800 \mathrm{IU} / \mathrm{kg} \mathrm{LMWH}$ to the rabbits significantly prolonged aPTT (Table 1). The rLopap-treated groups (LG1 and LG10) showed a dose-dependent decrease in aPTT 10 and 20 min after administration of the compound compared to $S G$ and $C G(P<0.01)$.

\section{Hematological parameters}

There were no statistically significant differences in hematocrit (Figure $5 \mathrm{~A}$ ) or platelet numbers (Figure $5 \mathrm{~B}$ ) among the groups at any times tested.

\section{Discussion}

rLopap is the first exogenous prothrombin activator that shows serine protease-like activity, independent of prothrombinase components (6) and unique lipocalin activity that interferes with hemostasis mechanisms (7). Members of the lipocalin family are recognized as carriers of small lipophilic molecules, regulators of metabolic and homeostatic processes, and share three characteristic conserved domains in their primary structure (9). Furthermore, Lopap has no similarities with other known prothrombin activators, including those from snake venoms or serine proteases.
Table 1. Activated partial thromboplastin time (aPTT) following pretreatment with low molecular weight heparin $(\mathrm{LMWH}, i v)$ and treatment with recombi-

\begin{tabular}{|c|c|c|c|c|}
\hline \multirow[t]{2}{*}{ Groups } & \multirow[t]{2}{*}{ Baseline } & \multirow{2}{*}{$\begin{array}{c}\text { After LMWH } \\
5 \mathrm{~min}\end{array}$} & \multicolumn{2}{|c|}{ After rLopap } \\
\hline & & & $10 \mathrm{~min}$ & $20 \mathrm{~min}$ \\
\hline Control & $28.4 \pm 2.6$ & $27.9 \pm 2.0$ & $28.1 \pm 2.5$ & $28.2 \pm 2.3$ \\
\hline Saline & $26.8 \pm 3.8$ & $>350.0 \pm 0^{*}$ & $>350.0 \pm 0^{*}$ & $>350.0 \pm 0^{*}$ \\
\hline LG1 & $27.7 \pm 2.3$ & $>350.0 \pm 0^{*}$ & $234.3 \pm 22.0^{+\star}$ & $227.6 \pm 14.0^{+\star}$ \\
\hline LG10 & $28.5 \pm 3.1$ & $>350.0 \pm 0^{*}$ & $168.9 \pm 24.0^{+\star \#}$ & $157.8 \pm 21.0^{+\star \#}$ \\
\hline
\end{tabular}

Data are reported as means $\pm S D$ for $\mathrm{N}=5$ rabbits per group. $C \mathrm{C}=$ control group; $S G=$ saline group; $L G 1=1 \mu \mathrm{g} / \mathrm{kg}$ rLopap; $L G 10=10 \mu \mathrm{g} / \mathrm{kg}$ rLopap. ${ }^{+} \mathrm{P}<0.01 \mathrm{vs}$ saline group. ${ }^{*} \mathrm{P}<0.01$ vs control group. ${ }^{\#} \mathrm{P}<0.01$ vs LG1 (ANOVA).

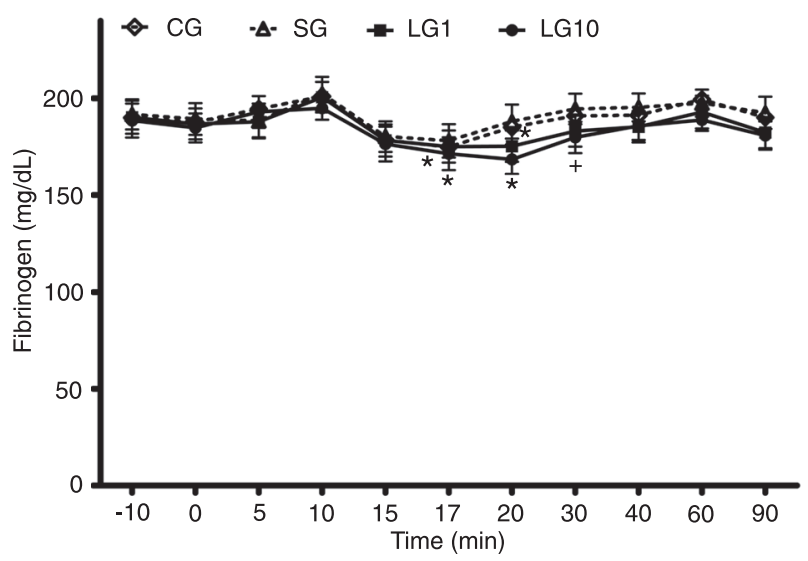

Figure 4. Fibrinogen level. $C G=$ Control group; $S G=$ saline group; LG1 = $1 \mu \mathrm{g} / \mathrm{kg}$ recombinant Lopap (rLopap); LG10 $=10$ $\mu \mathrm{g} / \mathrm{kg}$ rLopap. Data are reported as means \pm SD for $\mathrm{N}=5$ rabbits per group. ${ }^{*} \mathrm{P}<0.01$ vs saline group; ${ }^{+} \mathrm{P}<0.05$ vs saline group (ANOVA).
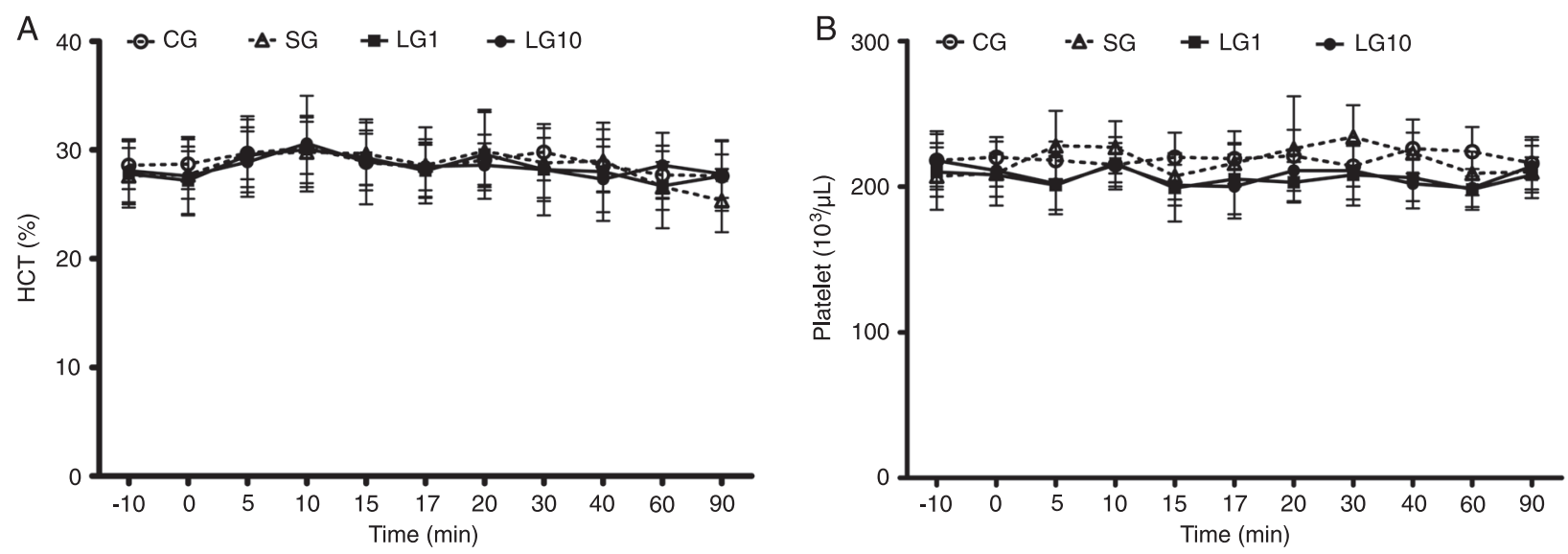

Figure 5. Hematocrit $(\mathrm{HCT}, A)$ and platelet count $(B)$. CG = Control group; SG = saline group; $\mathrm{LG} 1=1 \mu \mathrm{gg} / \mathrm{kg}$ recombinant Lopap (rLopap); LG10 $=10 \mu \mathrm{g} / \mathrm{kg}$ rLopap. Data are reported as means $\pm \mathrm{SD}$ for $\mathrm{N}=5$ rabbits per group. 
In the present study, we investigated the effect of rLopap in controlling excessive bleeding when factor $\mathrm{Xa}$ is inhibited by LMWH. Factor Xa was inhibited by injecting a single dose of LMWH (1800 IU/kg). LMWH level was sustained along treatment, as demonstrated by anti-Xa levels (Figure 2B) and as previously demonstrated (8). A similar dose of LMWH (2 mg $\left.\mathrm{kg}^{-1} \cdot \mathrm{day}^{-1}, \mathrm{sc}\right)$ is used for treating patients with venous thromboembolism (10). However, a similar dose of LMWH in rabbits resulted in high anticoagulation, as previously described (8).

The peak blood activity of anti-Xa $(\sim 4 \mathrm{IU} / \mathrm{mL})$ was also higher than that previously reported with the same dose (10). This discrepancy in peak blood activity is probably due to the different route used for the administration of $L M W H$ in the present study. It is a concern that high doses of LMWH may result in severe anticoagulation, which could prevent procoagulant drugs from reversing its effect. rLopap efficiently controlled the excessive bleeding induced with LMWH in rabbits. A single iv injection of rLopap $10 \mathrm{~min}$ after the administration of LMWH decreased the bleeding time and aPTT and increased the production of the F1+2 fragment, without an excessive consumption of fibrinogen. There was no alteration in anti-factor Xa activity, possibly because rLopap does not interfere with blood levels of heparin. Lopap is non-immunogenic and was well tolerated, with no significant change in blood pressure, heart rate or temperature following its administration (data not shown). In addition, rLopap seems to have a short half-life in the circulation and low doses do not cause disseminated intravascular coagulation, as suggested by our data (Figures 2A and Figure 4).

It is well known that Lopap induces clot formation in microvessels (11), does not activate factor $X$ or plasminogen, and has no fibrinogenolytic activity (12). In contrast

\section{References}

1. Hirsh J, Warkentin TE, Shaughnessy SG, Anand SS, Halperin JL, Raschke R, et al. Heparin and low-molecularweight heparin: mechanisms of action, pharmacokinetics, dosing, monitoring, efficacy, and safety. Chest 2001; 119: 64S-94S.

2. Hirsh J, Raschke R. Heparin and low-molecular-weight heparin: the Seventh ACCP Conference on Antithrombotic and Thrombolytic Therapy. Chest 2004; 126: 188S-203S.

3. Schulman S, Beyth RJ, Kearon C, Levine MN. Hemorrhagic complications of anticoagulant and thrombolytic treatment: American College of Chest Physicians Evidence-Based Clinical Practice Guidelines (8th Edition). Chest 2008; 133: 257S-298S.

4. Bolliger D, Szlam F, Azran M, Koyama K, Levy JH, Molinaro $\mathrm{RJ}$, et al. The anticoagulant effect of protamine sulfate is attenuated in the presence of platelets or elevated factor VIII concentrations. Anesth Analg 2010; 111: 601-608.

5. Crowther MA, Warkentin TE. Bleeding risk and the management of bleeding complications in patients undergoing anticoagulant therapy: focus on new anticoagulant agents. to physiological prothrombin activation by factor $\mathrm{Xa}$ in the prothrombinase complex, no meizothrombin is formed by Lopap $(6,7)$. The thrombin generated by the action of Lopap is recognized by the platelet receptors (12). Thrombin is a platelet activator and, once it is activated, platelets expose integrin glycoprotein Ilb/IIla on their surface favoring the binding of plasma fibrinogen (13). Note that in the present study the fibrinogen levels decreased slightly at 10 and 20 min after the injection of rLopap. rLopap seems to override the anticoagulant effect of LMWH most likely due to its indirect action upon the platelets. The initial amount of thrombin produced may not be enough to convert a significant amount of fibrinogen into fibrin. However, it may cleave the von Willebrand factor from its complex with FVIII and consequently activate platelets in vivo (14-16). Activated platelets facilitate the formation of coagulation complex (prothrombinase), which generates enough thrombin to convert fibrinogen into fibrin $(14,16)$.

rLopap is the first described exogenous prothrombin activator capable of reversing bleeding induced by LMWH, opening new avenues for blocking uncontrolled anticoagulation. Further studies are required to better characterize the action of rLopap, and also to verify if it has a similar effect in reversing the new anti-Xa synthetic anticoagulant drugs.

\section{Acknowledgments}

Research supported by Instituto de Ensino e Pesquisa, Hospital Sírio Libanês, and FAPESP, CAT/CEPID, CNPq/ INCT. L. Wlian and L.C. Carrijo-Carvalho are recipients of scholarships from FAPESP. L.C. Carrijo-Carvalho is the recipient of a post-doctoral fellowship from CAT/CEPID FAPESP (\#2010/00600-0).
Blood 2008; 111: 4871-4879.

6. Reis CV, Portaro FC, Andrade SA, Fritzen M, Fernandes $\mathrm{BL}$, Sampaio CA, et al. A prothrombin activator serine protease from the Lonomia obliqua caterpillar venom (Lopap) biochemical characterization. Thromb Res 2001; 102: 427436.

7. Reis CV, Andrade SA, Ramos OH, Ramos CR, Ho PL, Batista IF, et al. Lopap, a prothrombin activator from Lonomia obliqua belonging to the lipocalin family: recombinant production, biochemical characterization and structure-function insights. Biochem J 2006; 398: 295-302.

8. Chan S, Kong M, Minning DM, Hedner U, Marder VJ. Assessment of recombinant factor VIla as an antidote for bleeding induced in the rabbit by low molecular weight heparin. J Thromb Haemost 2003; 1: 760-765.

9. Chudzinski-Tavassi AM, Carrijo-Carvalho LC, Waismam $\mathrm{K}$, Farsky SH, Ramos $\mathrm{OH}$, Reis CV. A lipocalin sequence signature modulates cell survival. FEBS Lett 2010; 584: 2896-2900.

10. Hyers TM, Agnelli G, Hull RD, Morris TA, Samama M, Tap- 
son $\mathrm{V}$, et al. Antithrombotic therapy for venous thromboembolic disease. Chest 2001; 119: 176S-193S.

11. Reis CV, Farsky SH, Fernandes BL, Santoro ML, Oliva ML, Mariano $\mathrm{M}$, et al. In vivo characterization of Lopap, a prothrombin activator serine protease from the Lonomia obliqua caterpillar venom. Thromb Res 2001; 102: 437-443.

12. Chudzinski-Tavassi AM, Schattner M, Fritzen M, Pozner $R G$, Reis CV, Lourenco D, et al. Effects of lopap on human endothelial cells and platelets. Haemostasis 2001; 31: 257265.

13. Wang WY, Wu YC, Wu CC. Prevention of platelet glycoprotein Ilb/IIla activation by 3,4-methylenedioxy-beta-nitrostyrene, a novel tyrosine kinase inhibitor. Mol Pharmacol 2006; 70: 1380-1389.

14. Bijsterveld NR, Moons AH, Boekholdt SM, van Aken BE,
Fennema $\mathrm{H}$, Peters $\mathrm{RJ}$, et al. Ability of recombinant factor VIla to reverse the anticoagulant effect of the pentasaccharide fondaparinux in healthy volunteers. Circulation 2002; 106: $2550-2554$

15. Johannessen M, Nielsen G, Nordfang O. Comparison of the factor VII:C clot analysis and a modified activated factor VII analysis for monitoring factor VII activity in patients treated with recombinant activated factor VII (NovoSeven). Blood Coagul Fibrinolysis 2000; 11 (Suppl 1): S159-S164.

16. Firozvi K, Deveras RA, Kessler CM. Reversal of low-molecular-weight heparin-induced bleeding in patients with preexisting hypercoagulable states with human recombinant activated factor VII concentrate. Am J Hematol 2006; 81: 582-589. 